\title{
A STUDY ON EDUCATIONAL NEEDS OF ADULTS (ON THE EXAMPLE OF ZAPORIZHZHIA REGION RESIDENTS)
}

\author{
Serhii Pryima \\ Tavria State Agrotechnological University, Melitopol, Ukraine \\ pryima.serhii@gmail.com
}

\author{
Andrii Orlov \\ Melitopol Bohdan Khmelnytsky State Pedagogical University, Melitopol, Ukraine \\ orlov.socio@gmail.com
}
Olena Anishchenko
Institute of Pedagogical Education and Adult Education of NAES of Ukraine, Kyiv, Ukraine
anishchenko_olena@ukr.net

Ellina Pozdnyakova-Kirbyateva

Khortitsky National Training and Rehabilitation Academy, Zaporizhzhia, Ukraine cobrian1982@gmail.com

\begin{abstract}
Lifelong learning is a determining factor of the city's or region's successful socio-economic development, the development of its human potential, the basis for the regional education policy. The theoretical substantiation, development and experimental verification of the conceptual grounds of the regional education policy require a careful analysis of both the educational capacity of the region and the study of the educational needs of the region residents, which confirms the urgency of the integrated monitoring of citizens' educational needs and the level of their satisfaction. In order to identify the educational needs of Zaporizhzhia region residents and the level of their satisfaction, 400 respondents have been surveyed. The survey was conducted in the form of a standardised interview with the "face-to-face" method according to the respondents' residence using a specially designed tool (a questionnaire) which included 20 principal questions and 9 questions of socio-demographic character. The structure of the interview was developed in accordance with the specific features of the research topic and it was divided into conventional blocks, including identification of the current state of the education services market in the region and assessment of its strengths and weaknesses, analysis of the structure of the education services market in the region, studying the educational demands and needs of the region residents, and mapping the potential possibilities for the development of the education services market. According to the results of the study, it was concluded that $57.5 \%$ of Zaporizhzhia region residents are in need of educational services. The most important reasons indicated by the respondents is the acquisition of the knowledge necessary for achieving success in the profession (46.7\%), the opportunity to get a diploma, licence or certificate (30.1\%), the opportunity to increase chances in the labour market (19.2\%). The inhabitants of the region mostly get information from the Internet $(62.0 \%)$. The analysis of the survey results revealed the trends (the understanding how important the role of education throughout life is, the priority of educational activities regardless of age, the level and profile of previous education, the nature of employment, work experience, income or residence area of respondents, the increase in interest in getting educational services among the rural population of the region, the need to create conditions for the updating of knowledge and retraining, which is related to increasing competition in the labour market, the increase in demand for active and practically directed teaching methods) and the factors (accessibility and interconnection of different levels and forms of education, the need for constant dialogue and use of feedback mechanisms in the development and implementation of regional programmes and development strategies, the need to create experimental pilot projects as promising resource centres on management of regional education development) influencing education development in the region. The results of the study of the educational needs of the region residents can be used in order to identify the priority areas of the regional education policy.
\end{abstract}

Keywords: lifelong learning; adult education; learning city/learning region; educational needs; education services market.

\section{Introduction}

Lifelong learning is a determining factor in regional development, as well as a competitiveness factor of certain areas (either of a city or region) and the state as a whole. The ability to learn as a competitiveness factor of any city or region in a globalised world is the basis of the concept of learning cities and regions which is gaining popularity at present. Studying the foreign experience of introducing the concept of learning cities and regions and adjusting its progressive ideas to the national cultural and educational space is a prerequisite for the development of human capacity of Ukraine, the basis of the regional education policy and socio-economic growth of the state as a whole.

The relevance of the mentioned problem is confirmed by the realities of the current socio-economic situation in the south-east of Ukraine, in particular in Zaporizhzhia region. The entire economy of the southeastern part of Ukraine needs to reorient its production, and, consequently, to retrain the workforce. The problem is being exacerbated by the increase in the number of internally displaced people from the east of 
the country and the Republic of Crimea who also need retraining and further adaptation to new living conditions. The situation is complicated by the socio-demographic aspects of unemployment: more than $70 \%$ of the unemployed are women, $31 \%$ are young people. A separate and very important aspect of the problem is the fact that about $40 \%$ of the unemployed are citizens with higher education, the number of which every year is replenished at the expense of HEI's graduates who have not been able to orient themselves in the labour market situation and remained without their first place of employment.

Thus, the theoretical substantiation, development and experimental verification of the conceptual foundations of the regional education policy of Ukraine, oriented at the development of human capacity in each region, is relevant and timely. At the same time, the development of these conceptual foundations requires a detailed analysis of both the educational capacity of the region and the study of educational needs of the region residents. The research done on identifying the educational needs of the region residents and the level of their satisfaction allows us to determine the prospects for the development of the educational services market in Zaporizhzhia region.

\section{Research Problem Focus}

The substantiation of the conceptual foundations of learning cities and regions is provided in the works by Yarnit (2015), Longworth (2006), Morgan (1997), Rutten \& Boekema (2007), etc. In particular, Rutten and Boekema (2007) present current research in the theory and practice of interaction among all agents of regional education policy in Europe, the USA and South Africa within the implementation context of the concept of learning cities and regions. Jordan, Longworth and Osborne (2013) show the genesis of the concept of a "learning city". Noteworthy is the publication by Lukianova (2016) dealing with the study of the adult learning motivation. The author analyses the influence of external and internal factors on the effectiveness of adult learning and examines a variety of approaches applied to the typology of internal motivation.

At the same time, in the theory and practice of scientific-methodological, legislative, organisational and managerial provision of the educational sphere in the context of the policy of regional development of Ukraine the problem raised has not been adequately reflected. In particular, there are no works in which mechanisms would be presented for monitoring and diagnosing the results of the education policy in the region regarding sustainable regional development, as well as there is no research studying the correlation of different types of education (formal, nonformal and informal), optimal methods and technologies of lifelong learning in the development of specific educational practices of the region, recommendations for the adoption of optimal managerial decisions in the field of education in the region, etc.

Formation and implementation of the education policy of regional development will actualise the research aimed at identifying the educational needs of the region residents, which confirms the urgency of the integrated monitoring of citizens' educational needs and the level of their satisfaction.

The analysis of the practice of regional educational research has allowed identifying individual attempts to study the regional educational needs of different countries. In particular, the purpose of the study within the framework of the Belarusian-German project "The Learning Region: Education for All Generations" was to determine the state and tendencies of the educational needs of the inhabitants of Vitebsk and Minsk oblasts of the Republic of Belarus (Learning region: education for all generations).

At the same time, there were no comprehensive studies on identifying the educational needs of the inhabitants of individual cities and regions in Ukraine, in particular in Zaporizhzhia region. This makes impossible the practice of effective management decisions in the area of regional education policy in the region. Thus, the purpose of the publication is to highlight the results of the study of educational needs of Zaporizhzhia region residents for the theoretical substantiation, development and experimental verification of the conceptual foundations of the regional education policy.

It should be noted that our previous publication (Pryima, Orlov, Anishchenko \& Kuchyna, 2017) presents the initial results obtained in the course of the conducted research processing. In contrast to the work mentioned above, the proposed article substantiates the formation of the research sample in accordance with the general population; stratification of the sample is presented through the distribution of the sample into urban and rural population; the age and gender distribution of respondents in the sample is specified, and the specific features of respondents' interviewing are disclosed. Considerable attention is paid to the visualisation of the rating of the most urgent reasons for obtaining educational services, to the priority of directions of non-formal education and the rating of timely programmes among the respondents of different groups. Compared with the results of the previous research (Pryima, Orlov, Anishchenko \& Kuchyna, 2017), the new ones are those which concern the analysis of such indicators as the level of awareness about 
educational services among the respondents of different age groups and the duration of the respondents' inclusion in the educational process within a week.

\section{Research Methodology}

For the theoretical substantiation of the conceptual foundations of the regional education policy, it is necessary to determine the current state of the prognostic conditions for the development of the learning region; to study regularities and principles of its functioning; to determine the indicators for the region to achieve the new social status. It is important to note that the practice of implementing the conceptual foundations of the learning region demonstrates the diversity of forms and methods of its implementation each region builds its own model, or rather, the development pathway which helps it to become competitive in the knowledge-based economy.

In order to identify the opinion of the inhabitants of Zaporizhzhia region regarding the most relevant educational needs, to determine the level of interest demonstrated by residents of different age groups towards participation in educational programmes and in order to find the promising directions of the development of the educational services market in the region, the staff of the Scientific and Methodological Centre for Adult Education and the Centre for Sociological Studies of Melitopol Bohdan Khmelnytsky State Pedagogical University conducted a questionnaire survey "Priority directions of education development in Zaporizhzhia region" through the period from May 4 to May 8, 2016. The survey was done in the form of a standardised interview on the basis of the "face-to-face" method at the place of respondents' residence.

\section{Research Toolkit}

The toolkit for the research was a standardised interview form, which included 20 thematic questions and 9 questions of socio-demographic character. The structure of the interview was developed in accordance with the specific features of the research topic and it was divided into conventional blocks:

- identification of the current state of the education services market in the region and assessment of its strengths and weaknesses;

- analysis of the structure of the education services market in the region;

- studying the educational demands and needs of the region residents, and mapping the potential possibilities for the development of the education services market.

The pre-survey toolkit was tested during a pilot study among residents of Melitopol and Melitopol district (urban and rural population) $(n=60)$, with the aim of clarifying the validity and reliability of the research. Thus, the necessary levels of operational, construct, internal and environmental validity of the toolkit and research methodology were achieved (Lahm, 2007), and the necessary conditions were created to achieve the representativeness of the research.

\section{Survey sample}

\section{General population}

The general population was the population of Zaporizhzhia region which is an administrative region in the south of Ukraine. The territory of the region is 27.18 thousand square kilometres, which is $4.5 \%$ of the territory of Ukraine. The population is 1 million 749 thousand people, which makes up $4.1 \%$ of the national population. The distribution of urban and rural population corresponds to the proportion of 3 to 1 and accounts for about $65 \%$ of the urban population and $35 \%$ of the rural population. The density of the population is not homogeneous and averages 64.97 people $/ \mathrm{km}^{2}$. The concentration of population accounts for the cities of regional significance.

The administrative centre is the city of Zaporizhzhia. The region comprises of 20 districts, 7 districts in cities and 950 settlements. Among them, there are 36 of urban type and 914 of rural type. There are 14 cities, 22 town-type settlements, 870 villages, and 44 settlements. In the region, 5 centres of economic, social and cultural attraction were historically formed, i.e. the cities of regional significance Zaporizhzhia, Melitopol, Berdyansk, Tokmak and Energodar.

In accordance with the structure of the general population, a survey sample was formed. The sample is unrepeatable, multi-stage, zoned, stratified, quota, random. The theoretical error placed in the sample for a confidence interval of $95 \%$ does not exceed $5 \%$. The number of respondents (n) is 400 .

\section{Sample design}

The sample zoning was conducted by analysing and comparing statistical data in all the districts of the region, regional centre and cities of regional significance with regard to population number and density, saturation with educational and cultural infrastructure, distance from centres of economic and social attraction (cities of regional significance) and availability of transport links with them. Thus, in accordance 
with zoning, 5 cities were distinguished and 5 larger conditional sub-districts were formed for conducting the research.

According to the demographic portrait of the region, as of May 1, 2016, and zoning of the survey sample, a proportional distribution of the number of respondents in each city and sub-district was formed (Fig. 1).

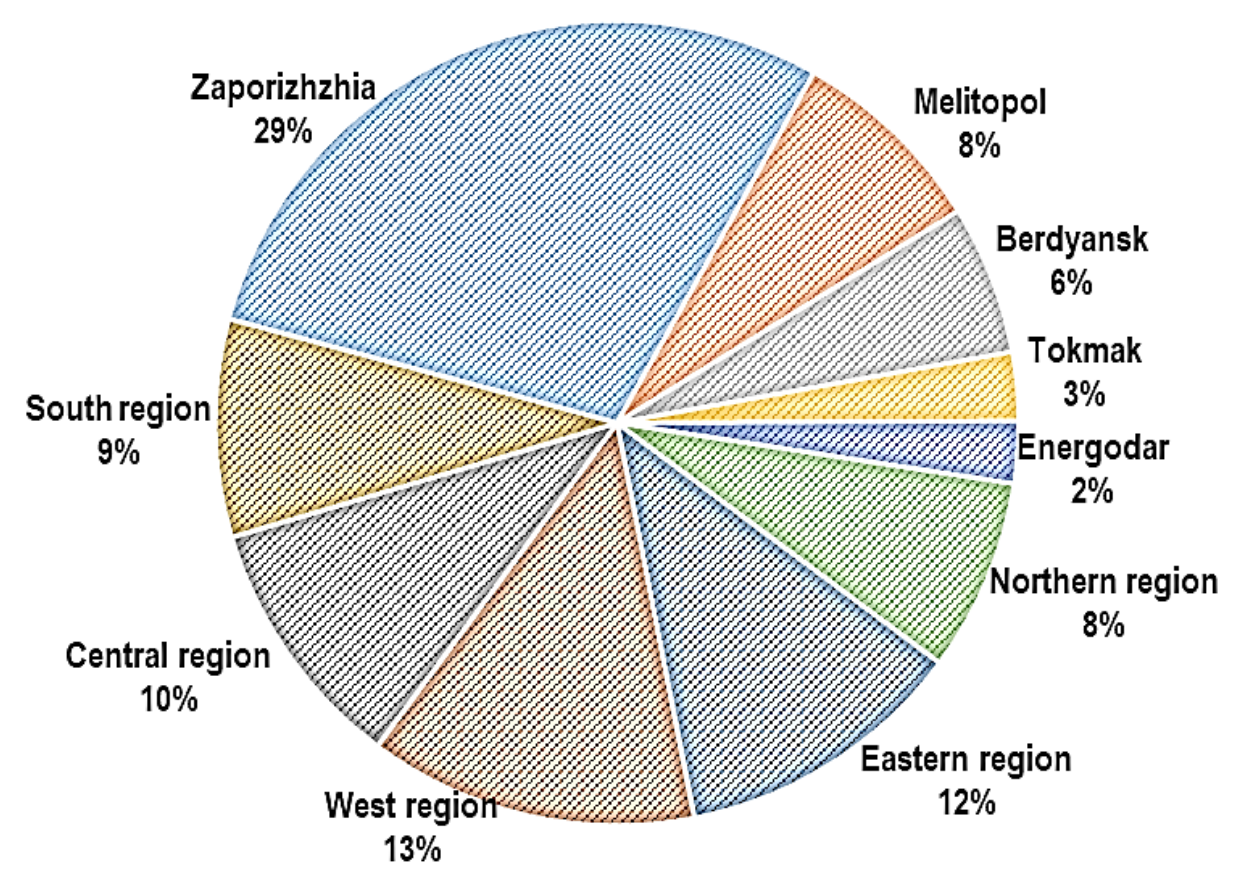

Fig.1. Rate of respondents in the selected cities of the region and sub-districts

The sample stratification was carried out by distributing the sample population to urban and rural population, according to the demographic portrait of the region as of May 1,2016. Thus, $63 \%$ of the urban population and $37 \%$ of the rural population participated in the research. (Fig. 2)

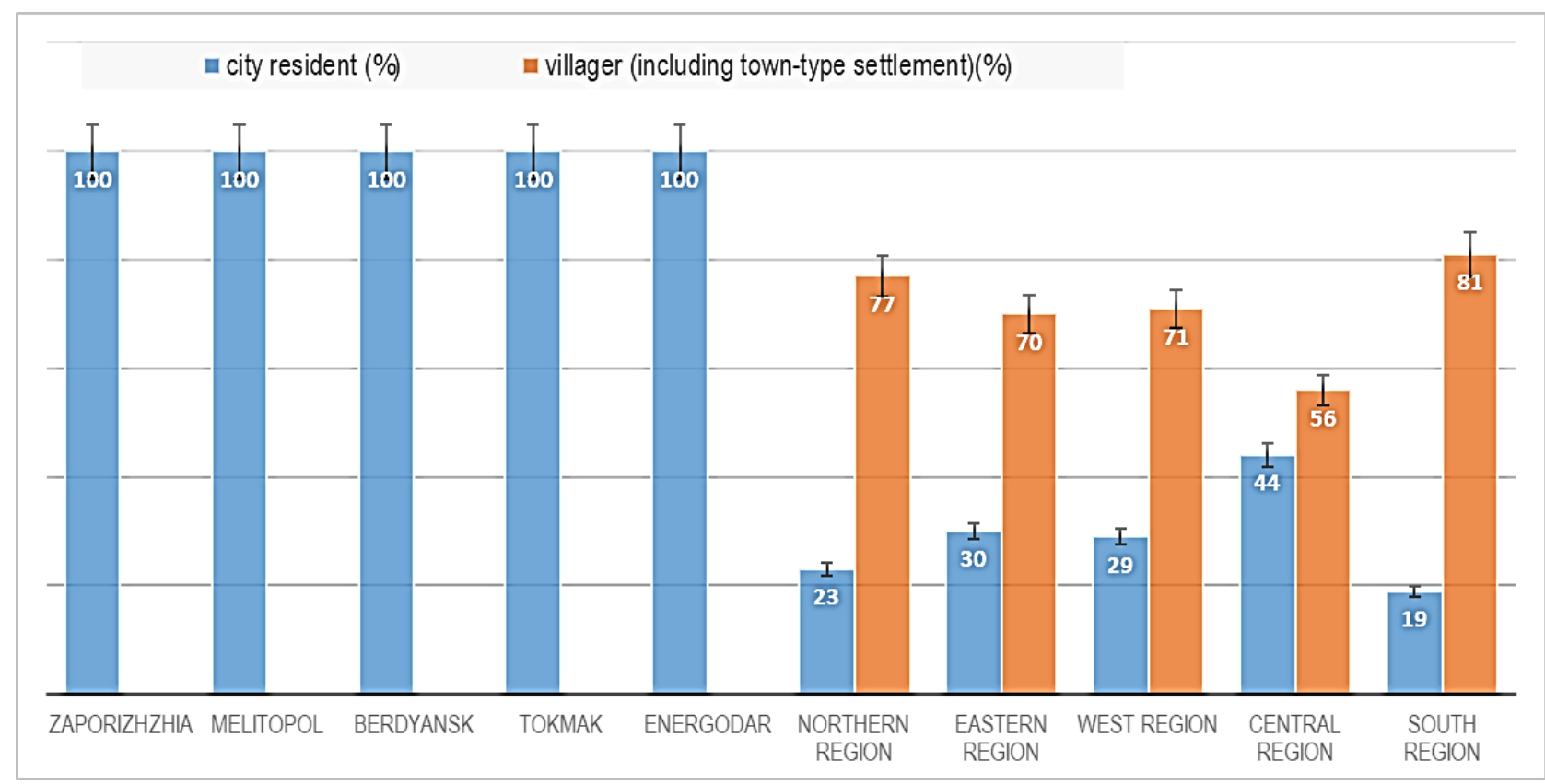

Fig.2. Rate of urban and rural population in the sample, according to the selected cities of the region and sub-districts

The quota selection was based on the criteria of the gender of respondents and the age group, which correspond to the statistical data regarding the selected cities and sub-districts and represent the sociodemographic structure of the region population as of May 1, 2016 (Fig.3). 


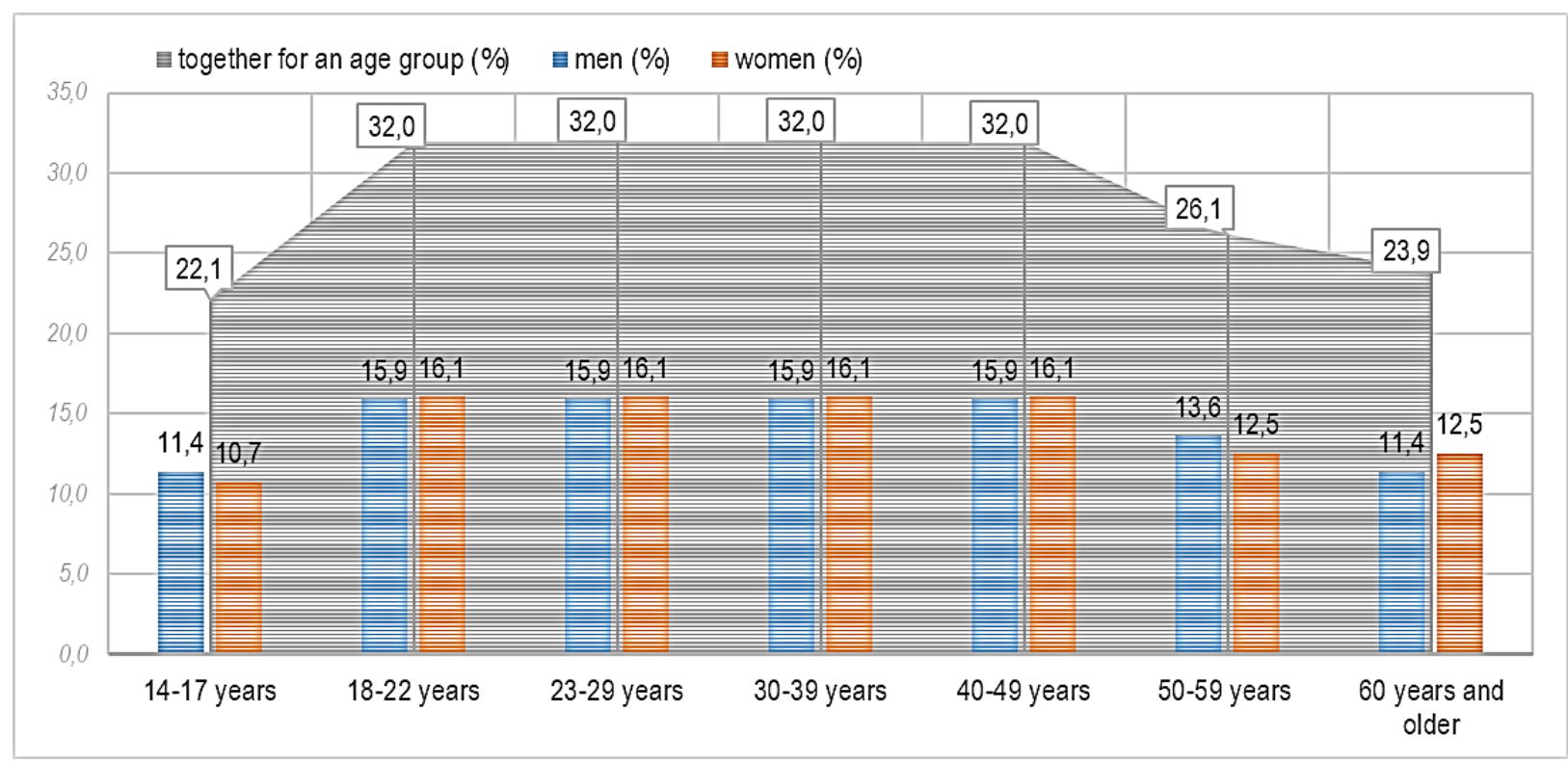

Fig.3. Age and gender distribution of respondents in the sample

At the last stage of selection, random selection was used, which allowed increasing the representativeness of the sample, to include as wide circle of respondents as possible in the survey without losing the quality of the result.

Immediately during the survey, the sample was adjusted according to the criteria such as education (primary, secondary, secondary vocational, basic higher and complete higher education), the nature of employment (persons working; persons in education; pensioners and non-working people), and level of wealth (persons with low, medium, high level of security).

\section{Specific features of research}

A certain proportion of those invited to participate in the research went back on the interview. Correspondingly, RESPONSE RATE was calculated as an average of $30.3 \%$ in the research. The main reasons for going back to the interview were: family events, links to employment, caution, social distrust. (Fig.4)

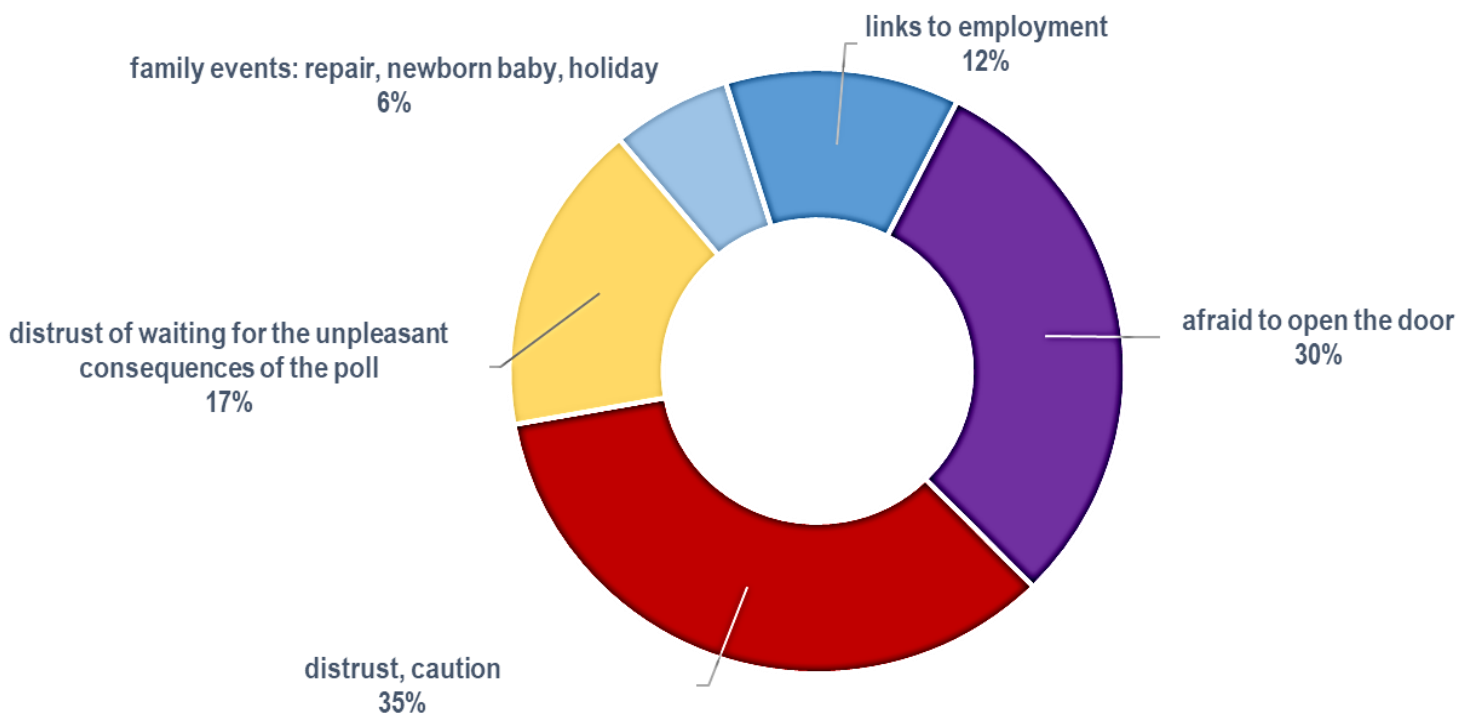

Fig.4. Response rate

In general, the proposed topic was interesting and understandable for all the respondents. However, the respondents became more active after being asked those questions of the interview which dealt with the potential possibilities of the education services market and their personal needs in educational products of a new format. When making judgments, most of the participants turned to their personal experience and the experience of their acquaintances. 


\section{Research Results}

According to the results of the study, it was concluded that $57.5 \%$ of Zaporizhzhia region residents are in need of educational services. At the same time, $15.5 \%$ have already decided on where they will receive them (see Fig.5).

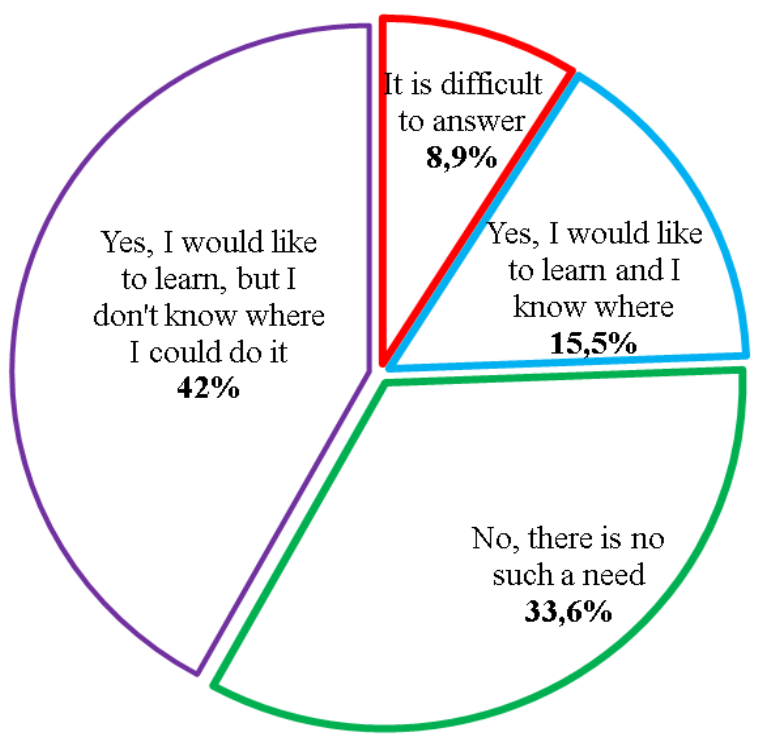

Fig.5. The need of respondents to get educational services $(\%),(n=400)$

Analysing the educational needs of different groups of the region residents, it turned out that today $90.4 \%$ of youth, $76.7 \%$ of middle-aged people and $41.3 \%$ of the third age group representatives have such needs. These indicators are also influenced by the level of respondents' education, since getting educational services is extremely urgent for those who now have general secondary education $(63.9 \%)$, secondary vocational education (50.5\%) and higher education (61.3\%) (in this case, the place of the respondents' residence does not matter). It should be noted that among low-income families, this need is slightly lower (44.4\%) than among those who have an average (55.6\%) and high (69.2\%) level of income.

The most important reason indicated by the respondents is the acquisition of the knowledge necessary for achieving success in the profession $(46.7 \%)$. The second place in the rating is the opportunity to get a diploma, licence or certificate $(30.1 \%)$. And the third place is the opportunity to increase chances in the labour market (19.2\%). That is, education, in this case, is inextricably linked with the labour market and personal success (career). And this is a normal mechanism for the functioning of these two systems, which is explained both by the requirements of time and global trends. However, at the moment, some other motives for getting education are present, such as self-development and self-improvement or boosting of social activity. After all, obtaining modern knowledge and mastering functional literacy (informational, legal, economic, etc.) takes only the fourth place (16.6\%) in the rating of reasons for education.

Among the less important reasons for getting educational services, respondents indicated (see Fig.6) the following: change of situation (7.4\%), increase of chances in personal life (6.6\%), obtaining knowledge for change of profession (6.0\%), direct demand of an employer $(5.7 \%)$ and participation in entrepreneurial activity $(4.9 \%)$.

The analysis of the data shows that the motive of "obtaining knowledge for successful career development" is significant for all age groups, although it is mostly indicated by the middle-aged representatives (49.2\%). It correlates with the increase of the level of education and income of respondents and it is of the highest importance for respondents with higher education (50.6\%), with an average (47.4\%) and high (47.4\%) incomes, and it is more relevant for the rural citizens (50.5\%).

Getting a diploma, licence or certificate is a more significant reason for young people $(49.5 \%)$ with secondary $(36.1 \%)$ or higher $(34.8 \%)$ education from families with a high level of income $(42.1 \%)$.

By contrast, education as an opportunity to increase chances in the labour market is more likely to be of interest to the representatives of the middle-aged (22.0\%) and third age (21.8\%) groups, who predominantly have a secondary vocational education $(22.2 \%)$. They represent low-income families $(66.7 \%)$ and mostly live in villages (22.4\%). 


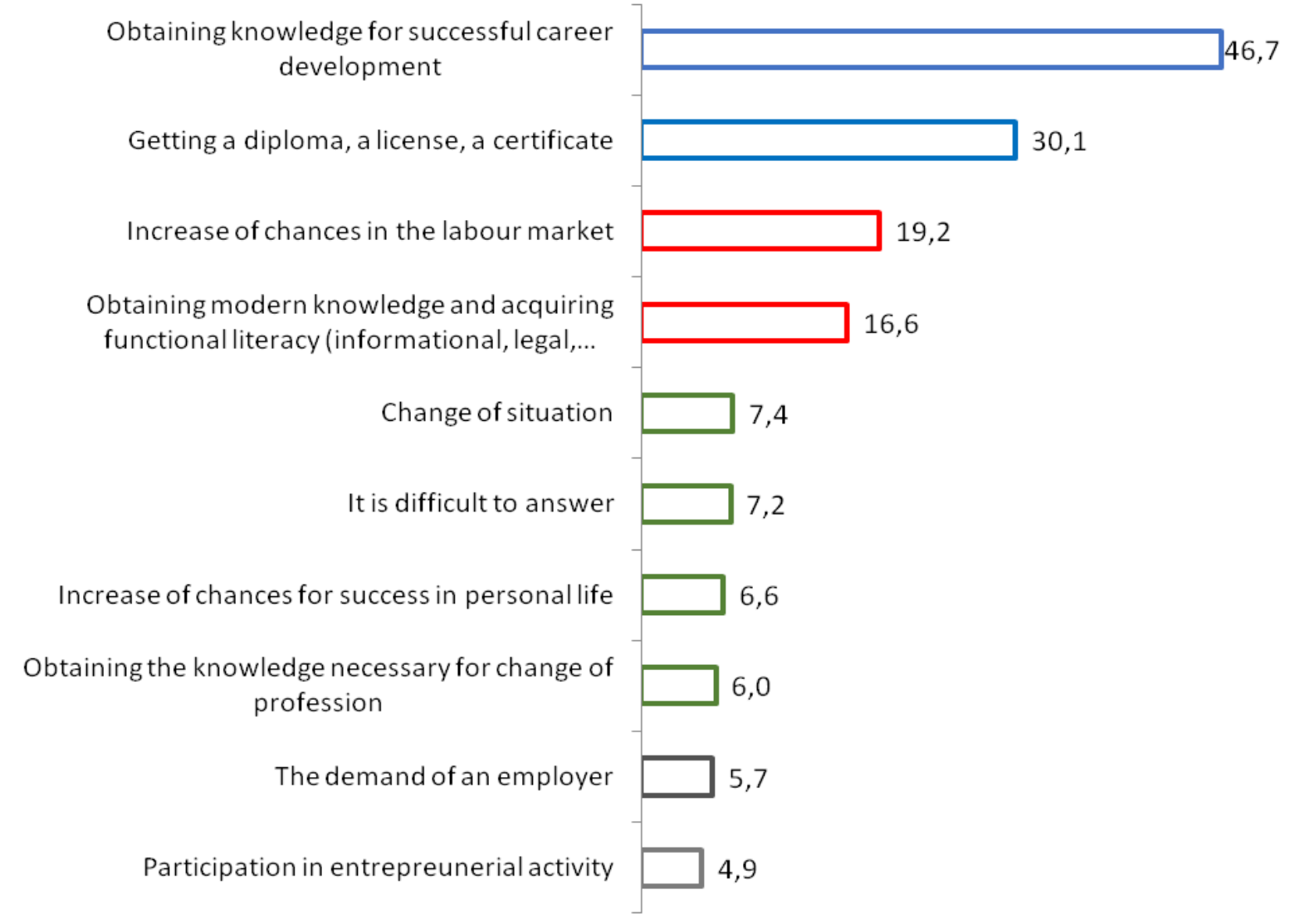

Fig.6. Reasons for getting educational services by respondents $(\%),(n=400)$

As for obtaining modern knowledge and acquisition of functional literacy (informational, legal, economic, etc.), that is, the understanding of education as a path for self-development, this reason is most significant for the middle-aged (25.4\%) with an average level of income (16.8\%) and is gaining importance with the growth of respondents' education in cities. Such results show: the priority of motivation for increasing the chances in the labour market since the age of 40 due to the risk of non-competitiveness; insufficient understanding of the need to acquire new knowledge for change of profession, especially through the modern reorientation of the economy; greater motivation to study among the rural population compared to the urban one; priority for educational activities regardless of age, level and profile of education, the nature of employment, length of employment, income, area of respondents' residence to obtain the knowledge necessary to succeed in a career and increase the chances in the labour market.

These results also emphasise the need to develop non-formal education systems that will be more flexible to the educational needs of the population and labour market requirements. $45.7 \%$ of respondents indicated that they were ready to receive education at non-formal education institutions (see Fig.7). At the same time, it should be noted that such an approach is acceptable for representatives of the third age group (59.3\%), which is complemented by the middle-aged group (40.0\%), and today they already have higher $(55.1 \%)$ or secondary vocational $(46.8 \%)$ education, that is, they have an occupation and certain experience.

Non-formal education is a more acceptable option for low-income people (71.4\%) and for almost half of those $(49.4 \%)$ with an average level of income. However, returning to the issue of motivation for getting an education, one can understand that non-formal education is a powerful mechanism for retraining in the labour market, for self-development and self-employment.

This fact was confirmed in the course of study of the ratings of thematic areas of non-formal education and programmes (courses) for the formation of new skills. Among the areas of non-formal education, the first place takes sports and recreation (33.3\%) (see Fig.8), which is relevant for young people (53.6\%), one third of the middle-aged group (36.7\%) and almost a quarter of the representatives of the third age group $(22.6 \%)$, all groups in terms of income, but mostly in rural areas (49.3\%). 


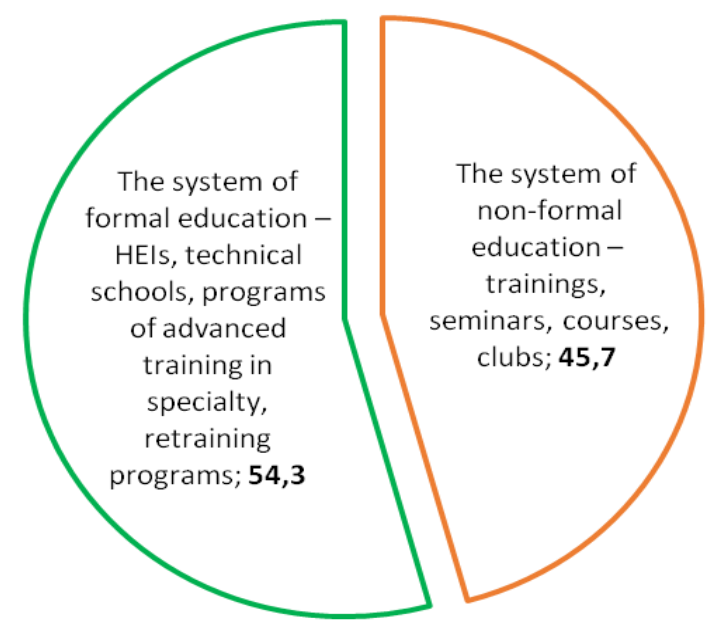

Fig.7. The level of respondents' interest in getting educational services of different formats $(\%)$, $(\mathbf{n}=\mathbf{4 0 0})$

The psychological direction takes the second place by its relevance for the inhabitants of the region. Almost a quarter of those polled indicated it (23.6\%). This direction is especially important for middle-aged residents $(50.0 \%)$ and a quarter of those of the third age (23.4\%), with secondary vocational (21.8\%) and higher (33.0\%) education and with an average $(24.7 \%)$ and low $(22.2 \%)$ income living in the cities of the region $(25.9 \%)$.

The third place is taken by the artistic-aesthetic direction (20.7\%). It is of interest to young people $(36.2 \%)$ and middle-aged people $(26.7 \%)$ who have secondary $(28.6 \%)$ or higher $(23.4 \%)$ education, an average $(21.0 \%)$ and high $(20.6 \%)$ income and live in cities $(22.9 \%)$. Although almost $15.5 \%$ of villagers have also emphasised this direction.

Further in the rating are the vocational and technical direction (folk crafts, handicrafts) (16.5\%), cooking (14.3\%), historical and cultural direction (13.5\%), language direction (11.8\%), family upbringing $(8.4 \%)$, fashion and style $(7.2 \%)$. The last position in this list is unfortunately taken by the patriotic and public direction, the relevance of which was determined only by $6.8 \%$ of the polled.

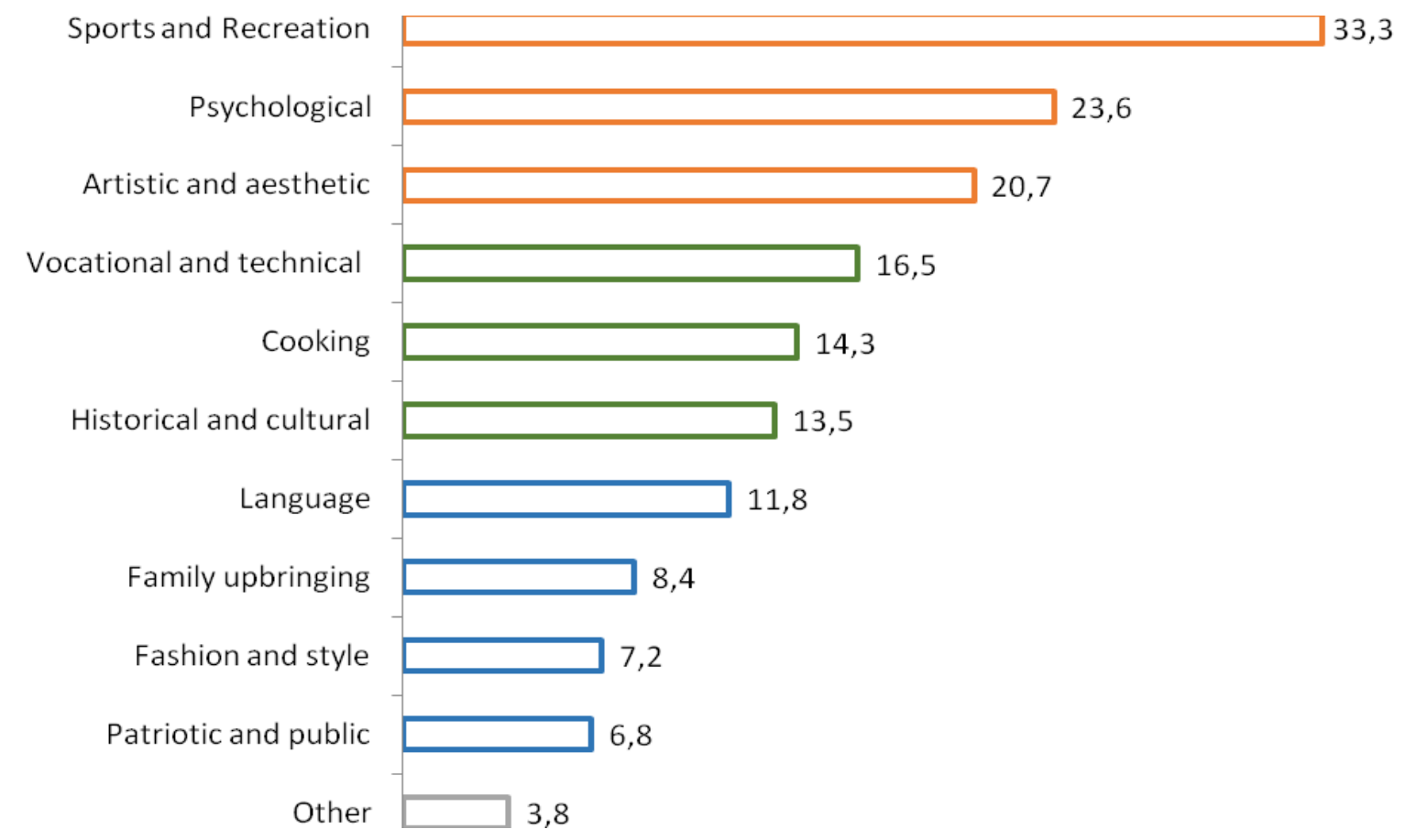

Fig.8. Relevance of non-formal education directions $(\%),(n=400)$ 
As for the programmes and courses on the formation of new skills, the first place among the region residents is given to language courses (29.0\%) (see Fig.9). Such programmes are relevant for young people (45.1\%), representatives of the middle-aged group (42.9\%) and one-fifth of the third age group representatives (19.2\%), all groups by level of education and income, regardless the place of residence.

The second place by relevance is taken by computer courses (21.6\%). And it is clear that this direction is especially important for the middle-aged group (32.1\%) and the third age group (21.2\%), with the higher $(27.8 \%)$ and secondary vocational $(21.2 \%)$ education, an average $(21.7 \%)$ and high $(21.1 \%)$ level of income, living primarily in rural areas (31.2\%).

Driving courses were defined by respondents as the third most relevant direction (20.4\%). Mostly they are indicated by young (35.2\%) and middle-aged people (32.1\%), with secondary $(30.5 \%)$ education, low income $(33.3 \%)$ living in rural areas $(26.0 \%)$, which shows that such programmes are an additional opportunity for this category of people to acquire new skills and use them for further employment, to increase their own chances in the labour market.

Business-courses are relevant for respondents (13.3\%), and turned out to be more interesting for the representatives of the middle-aged group (17.9\%) from rural areas (18.2\%). These programmes also serve as an opportunity for people to reorient in the labour market, but rather towards self-employment and starting up one's own business than hired labour.

Final positions by the level of residents' interest are taken by landscape design (4.7\%) and floristics (3.9\%).

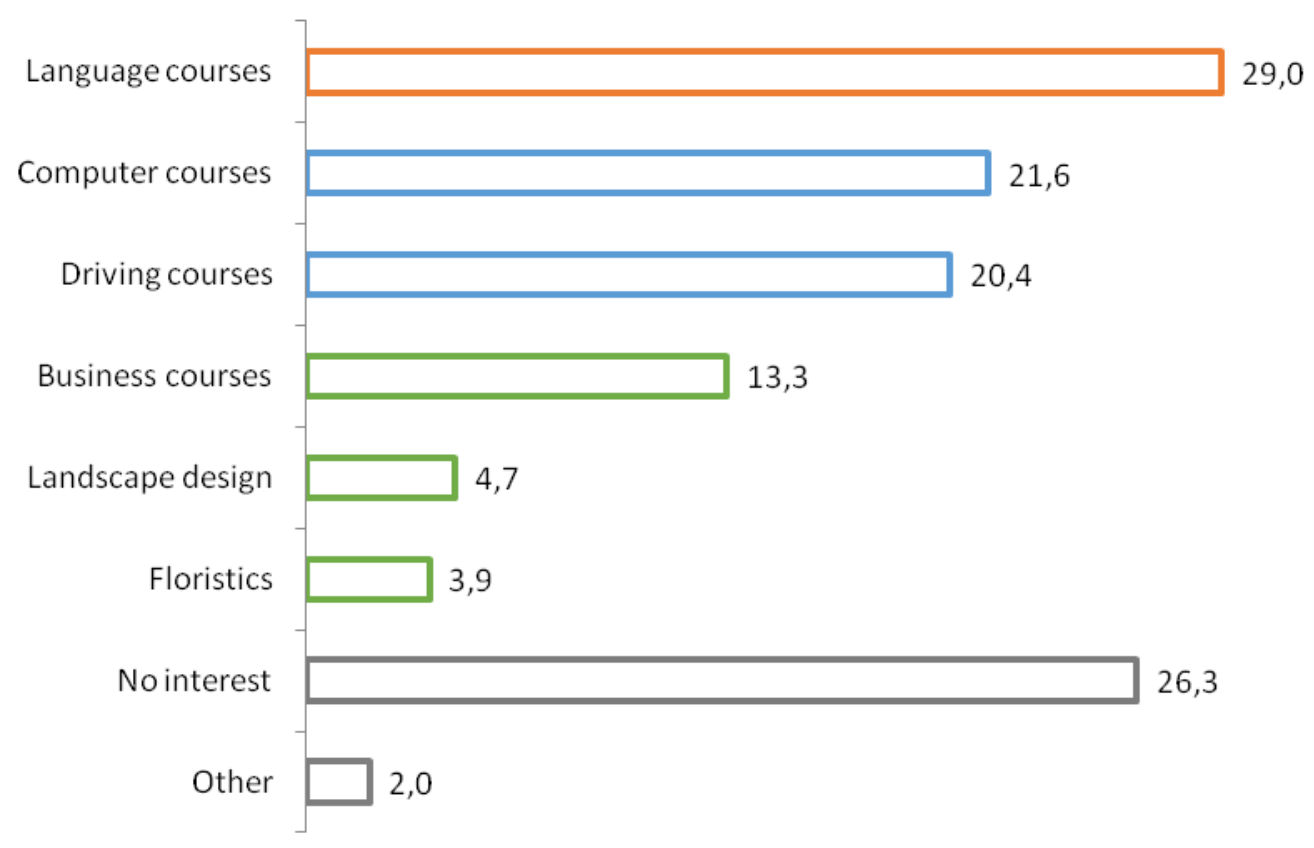

Fig.9. Relevance of programmes/courses on the formation of new skills $(\%),(n=400)$

The corresponding advantage of non-formal education is the fact that most of the inhabitants of the region (78.3\%) are not ready to spend much time on additional training. $40.7 \%$ of residents are willing to spend on training only 1-2 hours a week, and 37.6\% - no more than 2-4 hours a week. Only $15.9 \%$ of the inhabitants of the region are ready to study 3 days or more weekly (see Fig.10).

At this, a consistent tendency is observed: with the growth of respondents' age, the amount of time they are willing to spend on studying is decreasing. Thus, among those who are ready to study 4-6 hours a week there are mostly young people $(21.5 \%)$, and among the category of " $1-2$ hours a week" there are prevailing representatives of the third age $(50.7 \%)$. Although, it should be noted that both representatives of young (48.4\%) and middle-aged people (47.2\%) mainly consider the idea of additional training in the mode of $2-4$ hours a week. At the same time, there was no fundamental difference revealed between the inhabitants of the rural area and the city residents during the study. 


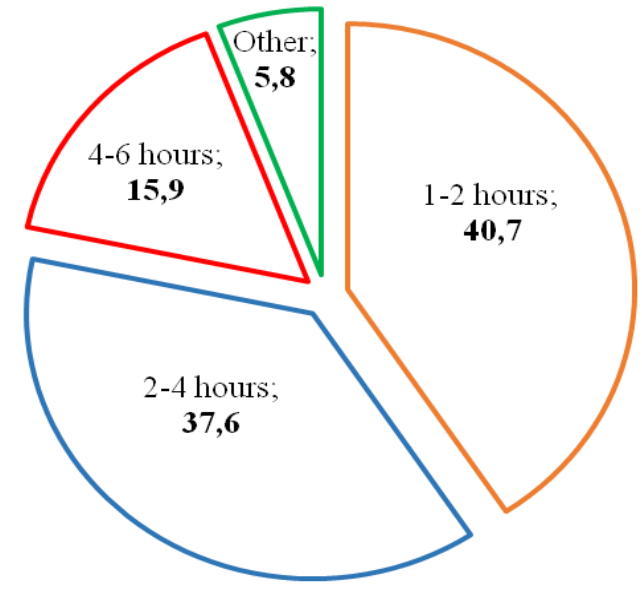

Fig.10. Amount of time (weekly) the residents of the region are willing to spend on $\operatorname{training}(\%)$, $(n=400)$

An important indicator is the awareness of respondents about educational services. In particular, more than half $(55.4 \%)$ of respondents have enough information about educational services in the region (see Fig.11).

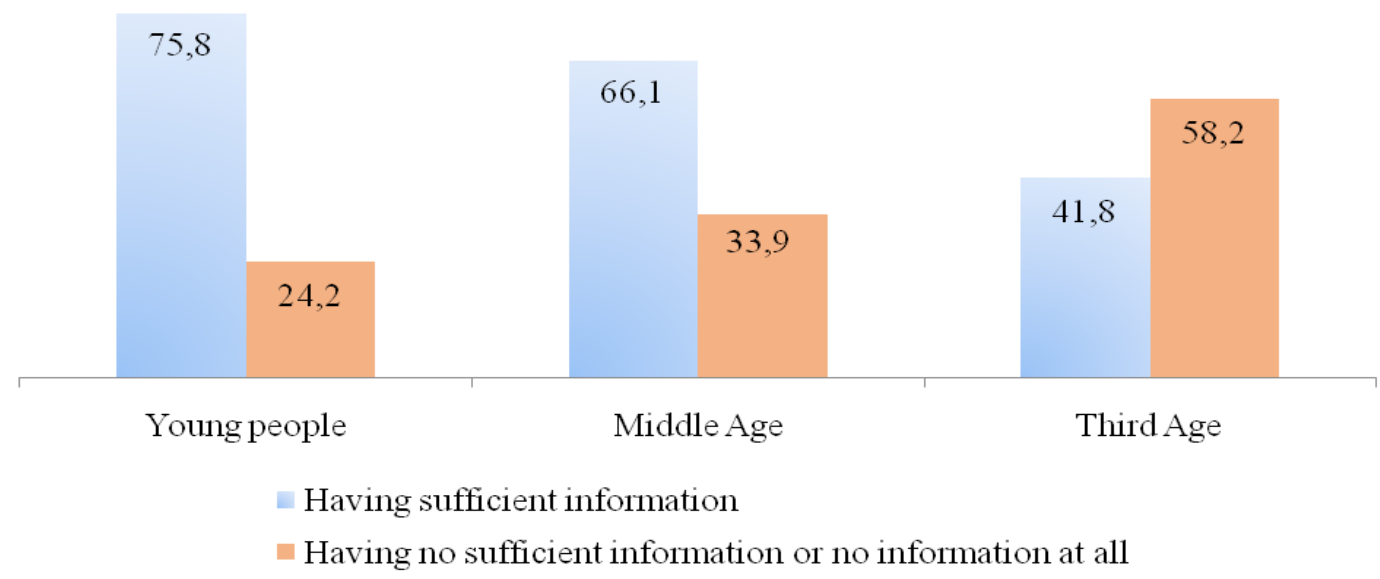

\section{Fig.11. Level of awareness about educational services among different age groups of the region residents $(\%),(n=400)$}

There is also a tendency towards a decrease in the level of awareness with an increase in the age of respondents. Thus, among young people, $75.8 \%$ have sufficient information about educational services, while more than half of the third age representatives (58.2\%) do not have such information. At the same time, again, the place of residence does not matter, since the level of awareness turned out to be independent of this factor.

The inhabitants of the region mostly get information from the Internet (62.0\%) (see Fig.11). These are mainly young $(83.7 \%)$ and middle-aged people (77.2\%). But, despite the existing stereotypes, this source of information is also used by $44.9 \%$ of the third age representatives. However, the main source of information for them remains the traditional means of communication (radio, television, newspapers) (43.2\%). For young people and middle-aged people, traditional sources of information are no longer relevant, as they are selected by a small percentage of these age categories ( $16.3 \%$ and $19.3 \%$, respectively).

\section{Discussion and conclusions}

The results of the survey made it possible to draw such conclusions. Firstly, the general tendency which is characteristic of the responses of all respondents is understanding how important the role of education throughout life is, the priority of educational activities regardless of age, level and profile of previous education, the nature of employment, work experience, income or residence area of respondents. Secondly, 
over the past decade, the interest in getting educational services has increased among the rural population of the region. The processes of decentralisation that are taking place in Ukraine today have been a catalyst for this interest, primarily in the field of civic education, and will further shape the request of rural citizens for educational services. Thirdly, there is an urgent need to create conditions for the updating of knowledge and retraining, which is related to increasing competition in the labour market; there is a need for modern highquality educational products, first of all among self-employed persons (entrepreneurs, persons without a permanent place of work). At the same time, educational services of sports and recreation, artistic and aesthetic, historical, cultural and psychological directions are in demand.

It should be noted that more attention should be paid to the research of stereotypes of perception of learning by respondents of all ages and insufficient knowledge of respondents regarding modern organisational forms and teaching methods. There is more demand for active and practically directed teaching methods from rural residents than from urban ones and interdependence of the chosen direction of non-formal education and the nature of respondents' employment.

The sociological research carried out in the course of the project on identifying the educational needs of Zaporizhzhia region residents and the level of their satisfaction has allowed identifying the factors that influence the development of education in the region, namely: accessibility and interconnection of different levels and forms of education; the need for cooperation and partnership among all stakeholders in the process of regional development, sharing the resources; the need for constant dialogue and use of feedback mechanisms in the development and implementation of regional programmes and development strategies; the need to stimulate the development of social partnership by establishing permanent links between different institutions and organisations of formal and non-formal education; the need to expand the volunteer movement in the field of non-formal education; the need to create experimental pilot projects as promising resource centres on management of regional education development. The results of the conducted sociological survey can be used by state institutions and local authorities to form a regional education policy, by providers of educational services in the region in order to identify the priority areas of their own activity strategy.

\section{Acknowledgement}

The work is prepared as part of the project "Development of the Learning Region Concept as the Foundation for Effective Regional Education Policy (on the example of Zaporizhzhia region)".

\section{References:}

Jordan L., Longworth N., Osborne M. (2014). The Rise and Fall and Rise Again of Learning Cities. In: Zarifis G., Gravani M. (Eds.), Challenging the 'European Area of Lifelong Learning'. Lifelong Learning Book Series (vol 19, pp.273-284). Springer, Dordrecht. https://doi.org/10.1007/978-94-007-7299-1_24

Lahm, K. (2007). Quantitative Validity. The Blackwell Encyclopedia of Sociology. Malden; Oxford; Carlton Blackwell Publishing.

Learning region: education for all generations (2012-2014). Retrieved November 30, 2017, from http://www.dvvinternational.org.ua/belarus/projects/2014/learning-region-education-for-all-generations/.

Longworth, N. (2006). Learning Cities, Learning Regions, Learning Communities: Lifelong Learning and Local Government. N.Y.: Routledge.

Lukianova, L. (2016). Motivation Factors of Adult Learning. The New Educational Review, 44 (2), 223-230.

Morgan, K. (1997). The Learning Region: Institutions, Innovation and Regional Renewal. Regional Studies, 31(5), $491-503$. https://doi.org/10.1080/00343409750132289

Rutten, R., Boekema, F. (Eds.) (2007). The Learning Region: Foundations, State of the Art, Future. Edward Elgar Pub: Cheltenham, UK., https://doi.org/10.4337/9781847205537.00008

Yarnit, M. (2015). Whatever became of learning city? Journal of Adult and Continuing Education, 21 (2), 24-35, https://doi.org/10.7227/jace.21.2.3

Pryima, S.M., Orlov, A.V., Anishchenko O.V. \& Kuchyna, K.O. (2017). Osvitni potreby zhyteliv Zaporizkoi oblasti: stan i potentsial dlia rozvytku rehionu, shcho navchaietsia [Educational Needs of Zaporizhzhia Region Residents: State and Potential for The Learning Region Development]. Science and Education, 2, 95-111. https://doi.org/10.24195/2414-4665-2017-2-17 